\title{
Optimized Wideband Impedance Matching Balun for Conducting Two-Arm Antennas
}

\author{
Khalid F. A. Hussein \\ Microwave Engineering Department, Electronics Research Institute, Cairo 12622, Egypt \\ Correspondence should be addressed to Khalid F. A. Hussein; khalid_elgabaly@yahoo.com
}

Received 3 May 2014; Revised 20 August 2014; Accepted 11 September 2014; Published 14 October 2014

Academic Editor: Sembiam R. Rengarajan

Copyright ( 2014 Khalid F. A. Hussein. This is an open access article distributed under the Creative Commons Attribution License, which permits unrestricted use, distribution, and reproduction in any medium, provided the original work is properly cited.

\begin{abstract}
A split coaxial balun with a step transition of the inner conductor diameter is introduced to satisfy impedance matching between unbalanced feeder and balanced antennas. The location of the step transition along the axis of the balun and the diameter change are two dimensional parameters that are not present in the conventional split coaxial balun. These additional parameters, together with the double slot width, provide more flexibility to design the balun for better impedance matching. The effects of the three dimensional parameters on the input impedance seen at the (unbalanced) coaxial line side of the balun are investigated when it is terminated with specific lumped impedance at its (balanced) split side. An optimization procedure is introduced to arrive at the balun dimensional parameters to give the best matching with specific load impedance. The proposed balun is designed to feed (balanced) two-arm antennas such as the dipole and the bowtie antenna from $50 \Omega$-coaxial line. The electromagnetic simulation shows that the proposed balun results in a perfect impedance matching. A comparison with the performance of the conventional split balun used to feed a dipole antenna shows that the balun proposed in the present paper gives a much lower value of the return loss at the design frequency and a wider bandwidth for VSWR $\leq 1.5$. The simulation results obtained using the MoM are compared with experimental measurements showing good agreement.
\end{abstract}

\section{Introduction}

A balun (balanced-to-unbalanced) is a type of electrical transformer that can convert electrical signals balanced about ground (differential) to signals that are unbalanced (singleended) and the reverse. Two conductors having equal and opposite potential constitute a balanced line. Microstrip and coaxial cables use conductors of different dimensions; these are unbalanced. Baluns are widely used to connect balanced transmission line circuits to unbalanced ones. They are also often used to match between lines of different impedance.

Among the various types of passive baluns, the split coaxial balun is the most commonly used for feeding balanced antennas (such as the dipole antenna) from unbalanced feeder (such as the coaxial line) [1]. A broadband planar balun with coplanar waveguide-to-slotline transition for UHF applications $(0.2$ to $2 \mathrm{GHz})$ is introduced in [2]. This balun has the advantages of negligible insertion loss and very low amplitude and phase imbalance. Printed transmission line baluns are commonly used for impedance matching in planar circuits [3-7]. Transmission line baluns can be used for impedance matching in the design of active microwave circuits such as power amplifiers [8]. Transmission line baluns can be used for wideband antenna impedance matching such as Archimedean spiral antennas $[9,10]$.

The analytic methods applied to analyze passive baluns used for antenna impedance matching usually apply the approximate transmission line models. For example, in [11] a simple analytical transmission line model of a splitcoaxial balun is proposed and tested. It is based on the coupled symmetric transmission line approach. The model leads to a closed-form analytical expression for the termination impedance and the transfer function of the complete antenna system that includes antenna, balun, and a nonsplit coaxial line of certain length.

The split coaxial balun with a step transition of the inner conductor diameter introduced in this work can be considered as three successive air-filled coaxial waveguide sections as shown in Figure 1. The third section can be seen as a coaxial line with double slots in the outer conductor. This 


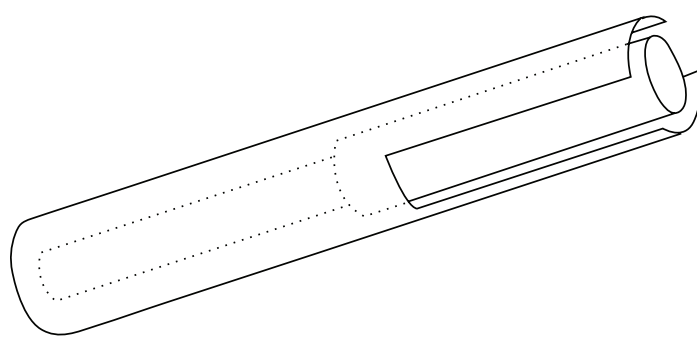

(a)

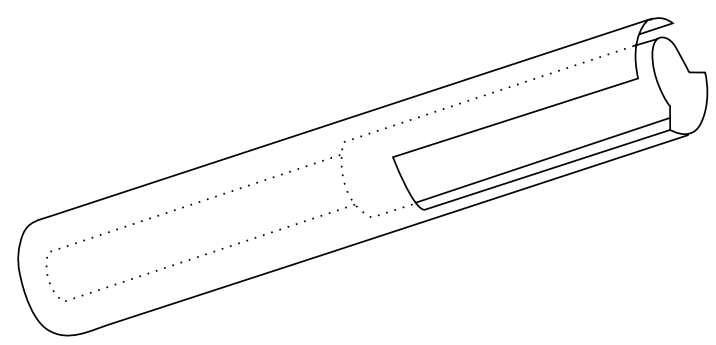

(b)

FIGURE 1: Split coaxial balun with a step-transition of the inner conductor: (a) waveguide transition from coaxial line to double-slotted coaxial line and (b) the same transition terminated with a short circuit at the double-slotted line side.

means that the balun structure has two longitudinal planes of symmetry perpendicular to each other. The symmetry of the proposed balun structure about each plane of symmetry implies the possibility of two guided modes: one of odd symmetry and the other of even symmetry of the transverse electric field about each plane of symmetry.

The present work uses the method of moments (MoM) to study the proposed balun characteristics and to evaluate the design parameters to satisfy impedance matching under various conditions. During numerical simulation, a circularly symmetric excitation source is attached to the balun at its unbalanced coaxial line side where a lumped load or a balanced antenna is attached to the unbalanced split line side of the balun. The excitation and load models are attached to the geometric model of the balun structure as described in [12].

\section{Split Coaxial Balun Structure}

The present work introduces a modified version of the conventional split coaxial balun with a step transition of the inner conductor diameter. A three-dimensional view of this balun is shown in Figure 1. The balun can be seen as composed of three successive transmission line sections as shown in Figure 2. Section 1 is a coaxial line with inner conductor of diameter $D_{1 \text { in }}$. Section 2 is a coaxial line with inner conductor of diameter $D_{2 \text { in }}$ and length $L_{t}$. Section 2 can be considered as a transitional transmission line section between sections 1 and 3. The total length of sections 1 and 2 is $L_{1 \text { out }}$. Section 3 is a split line with an inner conductor of diameter $D_{2 \text { in }}$, length $L_{2 \text { out }}$, and double slot in the outer conductor, where the angular width of each slot is $\theta_{s}$. A short circuit is made at the end of this section by connecting the inner conductor to one of the cylindrical strips as shown in Figure 1(b).

The step transition of the inner conductor gives more flexibility in impedance matching. This step transition adds two dimensional parameters: the inner conductor diameter $D_{2 \text { in }}$ and the transitional section length $L_{t}$. These additive dimensional parameters provide the balun designer with more degrees of freedom to arrive at better impedance matching over wide frequency band. One of the main goals of the present work is to investigate the effects of these dimensional parameters on the characteristics of the balun.

The split coaxial balun with the step transition of the inner conductor can be used to feed balanced two-arm antennas

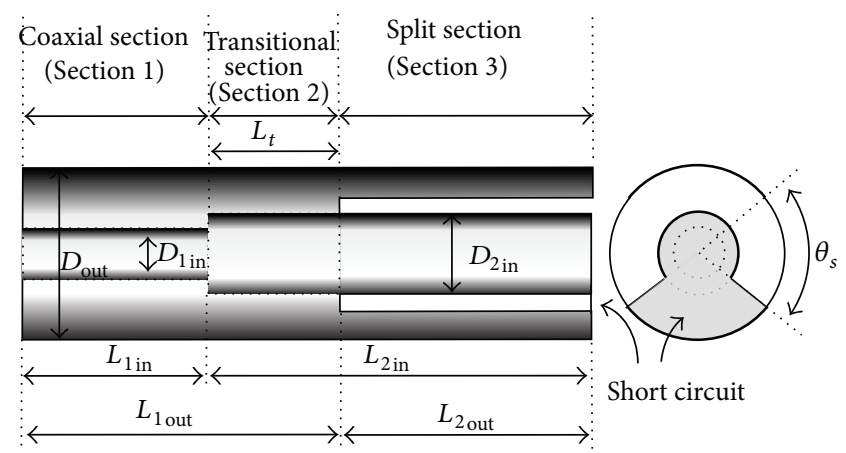

FIGURE 2: Dimensional parameters of the split coaxial balun.

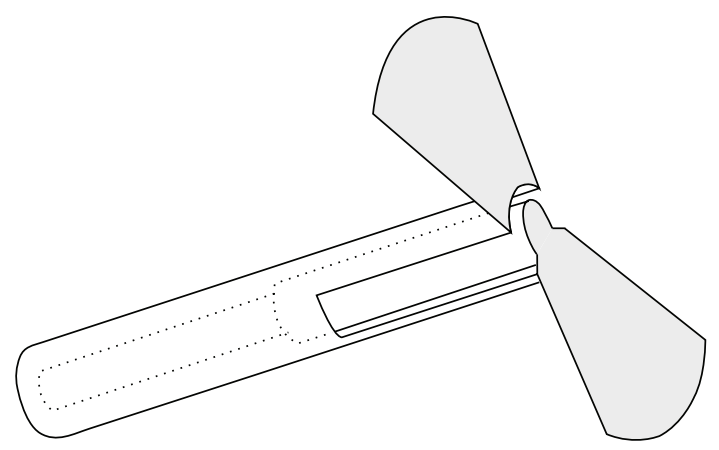

FIGURE 3: Split coaxial balun feeding a bowtie antenna (balanced load) through a coaxial line (unbalanced transmission line).

such as the bowtie antenna from unbalanced feeder such as the coaxial line as shown in Figure 3.

\section{Balance Ratio of the Balun}

The purpose of this section is to arrive at an expression for the balance ratio of a balun in terms of the currents at the feeding antenna port for subsequent numerical assessment of the balun performance. Consider a dipole antenna directly fed by a coaxial line without using a balun. As shown in Figure 4, while traveling within the transmission line, current $I$ flows on the inner conductor and $-I$ flows only on the inner surface of the coaxial line shield. When antenna current is flowing from left to right as shown, $I$ flows out of left 




(a)

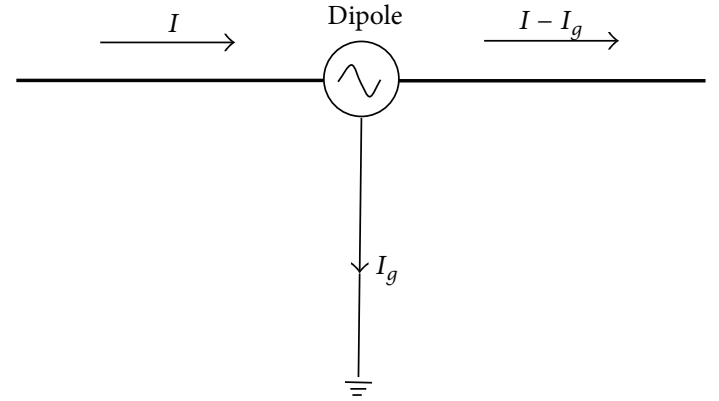

(b)

FIGURE 4: Current paths for a dipole fed by a coaxial line without a balun: (a) dipole antenna excited directly by a coaxial line without using a balun and (b) equivalent circuit of the radiating antenna arms.

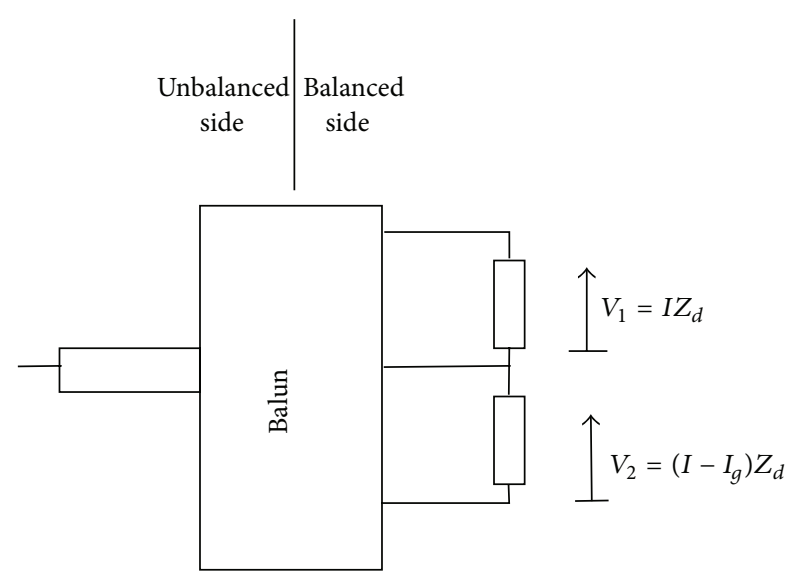

FIGURE 5: Equivalent circuit to evaluate the balance ratio of a balun.

arm of the dipole, downward onto the inner conductor, and returns to the generator. The current, $-I$, flows upward along the inside surface of the feed-line shield until it reaches the junction of the right arm of the dipole. At this junction, the current $-I$ divides into two separate paths to form $I-I_{g}$ and $I_{g}$. Current $I_{g}$ flows back down the outside surface of the feed line. The magnitude of $I_{g}$ depends on the impedance to ground determined by the outside surface of the coaxial shield.
If the effective path length to RF ground is an odd multiple of $\lambda / 4$, the impedance to ground will be very high, making $I_{g}$ negligible. In this case, the currents flowing in the dipole arms are nearly equal. On the other hand, if the RF path to ground is a multiple of $\lambda / 2$, the impedance to ground will be fairly low, and the current $I_{g}$ may be substantial. This results in unequal currents in the dipole arms, and, thus, the outer surface of the coaxial line shield effectively becomes a third arm of the antenna, which is connected in parallel with the right arm of the dipole. To clarify this connection of radiators, a simplified equivalent circuit is shown in Figure 4(b). Since currents $I$ and $-I$ do not interact with any other currents, we may hypothetically place the RF generator directly at the input terminals of the antenna. Thus, the coaxial cable is no longer needed to transfer power from the generator to the antenna. The third conductor of the feed line (the outside surface) can be replaced with a single wire connected between the right arm of the dipole and RF ground.

In Figure 4(a), it can be seen that, without a balun, changing the feed line length also means changing the length of the third arm of the radiating antenna, which in turn affects the impedance at the input end of the coaxial line. Therefore, the VSWR measured at the input of the coaxial line will change with the line length when no balun is present to eliminate $I_{g}$.

The balun works to eliminate or reduce the imbalance current, $I_{g}$, thus producing only two radiating arms with the currents flowing on them nearly equal. The efficiency of performance of a balun can be determined by its balance 


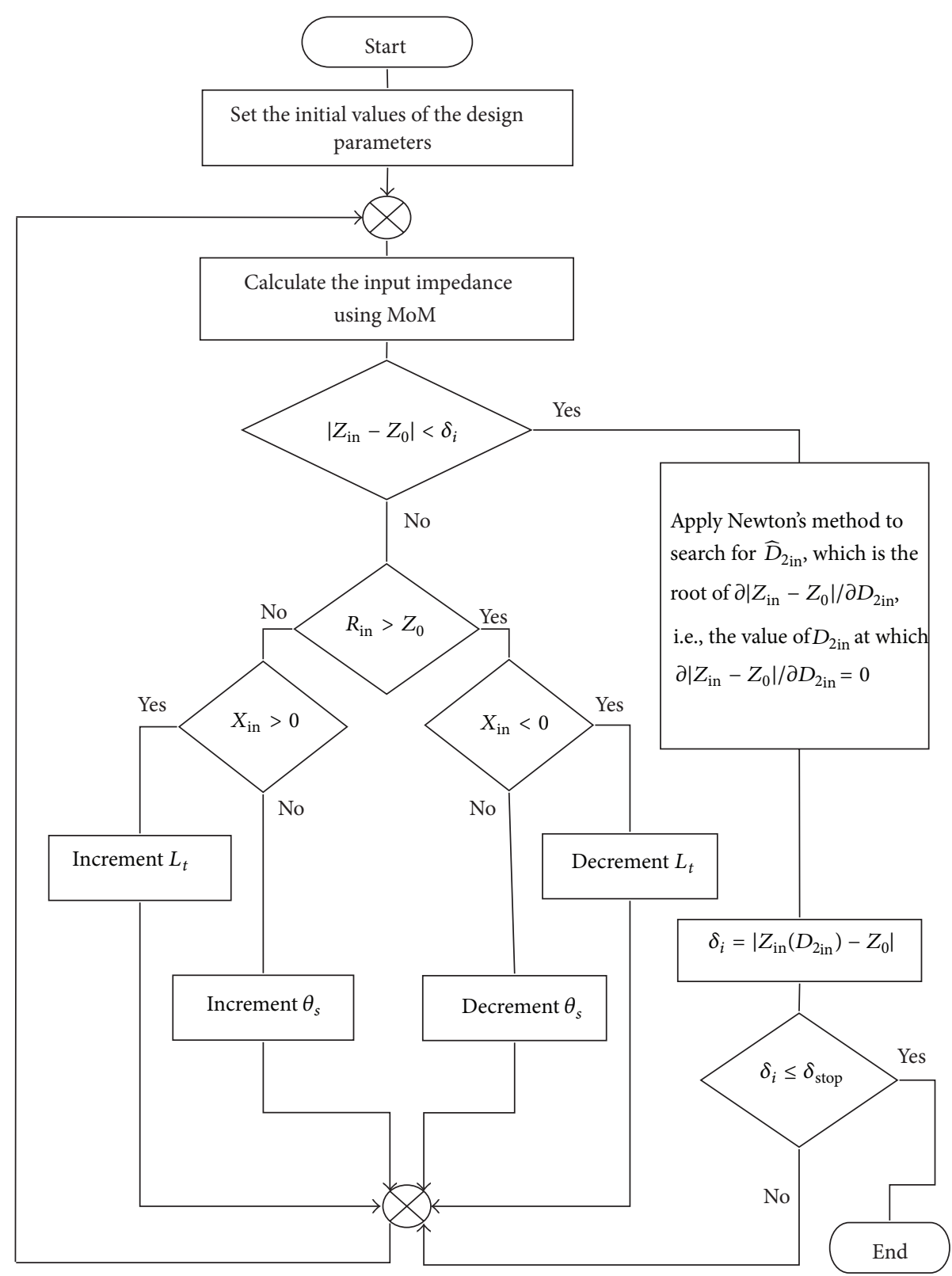

FIGURE 6: Flow chart for the optimization procedure to arrive at the dimensional parameters $L_{t}, \theta_{s}$, and $D_{2 \text { in }}$ for impedance matching between a coaxial feeder of characteristic impedance and balanced load.

ratio. Referring to Figure 5, the balance ratio can be defined as

$$
B=20 \log \left|\frac{V_{1}+V_{2}}{V_{1}-V_{2}}\right|,
$$

where $V_{1}$ and $V_{2}$ are the complex voltage drops across the left and right dipole arms, respectively, seen in Figure 4(a).

Considering that the dipole arms have the same equivalent impedance, the balance ratio can be defined as

$$
B=20 \log \left|\frac{I Z_{d}+\left(I-I_{g}\right) Z_{d}}{I Z_{d}-\left(I-I_{g}\right) V_{d}}\right|,
$$

where $Z_{d}$ is the equivalent impedance of the dipole arm. The last equation can be reduced to

$$
B=20 \log \left|\frac{2 I-I_{g}}{I_{g}}\right| .
$$

Thus, the balance ratio is increased by reducing the imbalance current $I_{q}$ and theoretically reaches $\infty$ when $I_{q}$ is eliminated. Practically, balance ratio of greater than $20 \mathrm{~dB}$ is acceptable. 


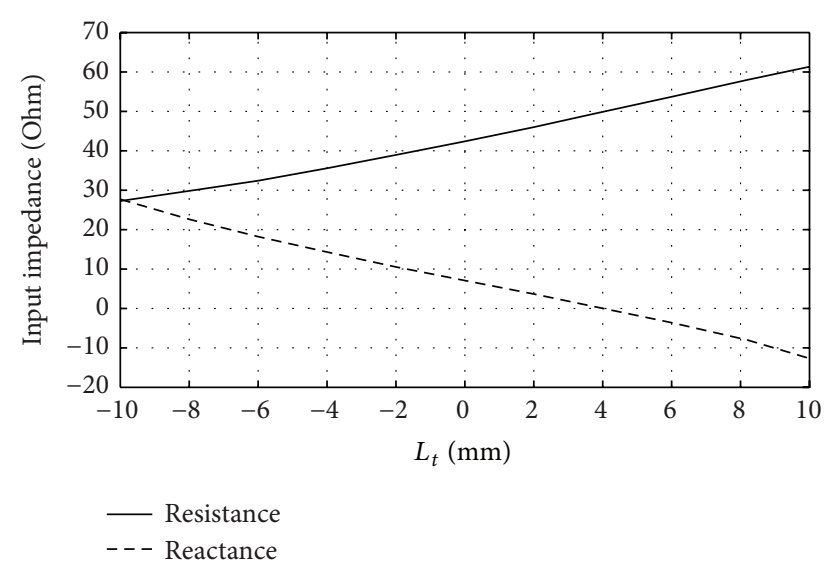

(a)

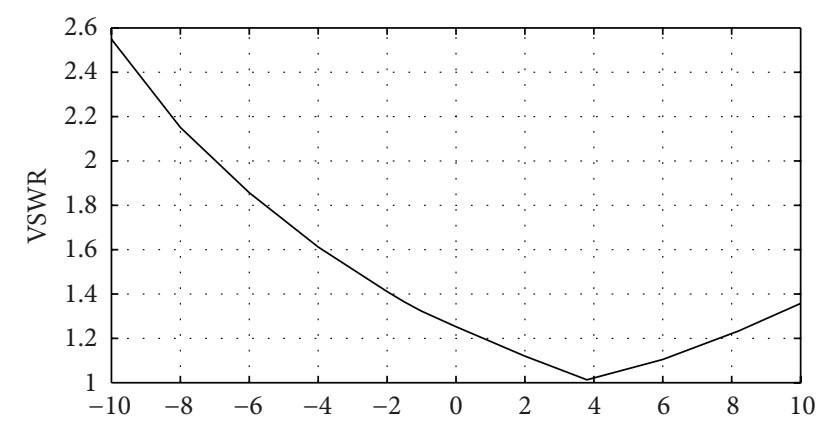

(b)

FIGURE 7: Variation of (a) the input impedance and (b) VSWR of a split coaxial balun excited at the coaxial line side and terminated at the split line side by a balanced $75 \Omega$ load with the length of the transitional section, $L_{t} ; f=2.0 \mathrm{GHz}, D_{\text {out }}=8 \mathrm{~mm}, D_{1 \text { in }}=3.5 \mathrm{~mm}$, $D_{2 \text { in }}=2.4 \mathrm{~mm}, L_{1 \text { in }}=6.34 \mathrm{~cm}, L_{2 \text { in }}=3.82 \mathrm{~cm}$, and $\theta_{s}=40^{\circ}$.

\section{Balun Optimization Procedure}

This section describes a systematic optimization procedure to arrive at the values of the three dimensional parameters $\left(L_{t}\right.$, $\theta_{s}, D_{2 \text { in }}$ ) so as to satisfy impedance matching given the values of the feeder and load impedances at the central frequency of the operating frequency band. This optimization procedure is presented as a flowchart in Figure 6 and can be described as follows.

(1) The total length of the balun $\left(L_{1 \text { out }}+L_{2 \text { out }}\right)$ is determined by the dimensional constraints imposed by the application. However, it is recommended that the balun length is not less than quarter the operating wavelength. This will be unchanged during the optimization procedure.

(2) Set the length of the split section ( $\left.L_{2 \text { out }}\right)$ equal to half the total length of the balun (i.e., $L_{1 \text { out }}=L_{2 \text { out }}$ ). This will be unchanged during the optimization procedure.

(3) Set the outer conductor diameter of the balun $\left(D_{\text {out }}\right)$ to the same value of the outer conductor of the coaxial feeder. This will be unchanged during the optimization procedure.



(a)

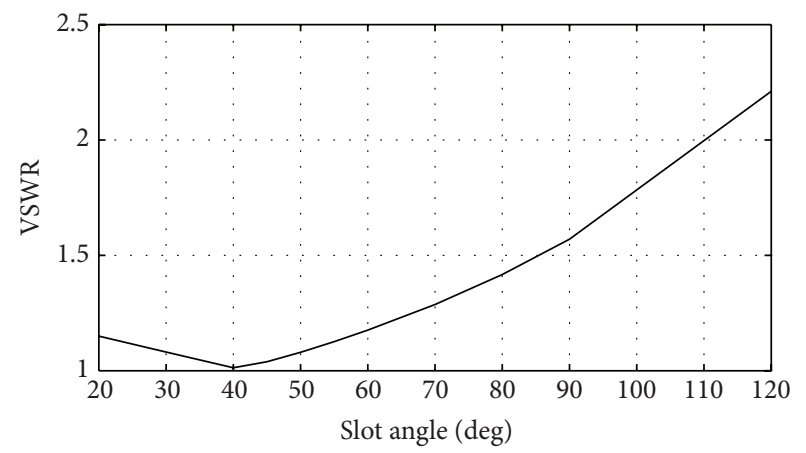

(b)

FIGURE 8: Variation of (a) the input impedance and (b) VSWR of a split coaxial balun excited at the coaxial line side and terminated at the split line side by $75 \Omega$-load with the slot angle; $f=2.0 \mathrm{GHz}$, $D_{\text {out }}=8 \mathrm{~mm}, D_{1 \text { in }}=3.5 \mathrm{~mm}, D_{2 \text { in }}=4.8 \mathrm{~mm}, L_{1 \text { out }}=6.72 \mathrm{~cm}$, $L_{2 \text { out }}=3.44 \mathrm{~cm}, L_{1 \text { in }}=6.34 \mathrm{~cm}, L_{2 \text { in }}=3.82 \mathrm{~cm}$, and $L_{t}=3.8 \mathrm{~mm}$.

(4) Set the inner conductor diameter of the coaxial line section of the balun $\left(D_{1 \text { in }}\right)$ to the same value of the inner conductor of the coaxial feeder. This will be unchanged during the optimization procedure.

(5) Initially, set the inner conductor diameter of the coaxial line section of the balun $\left(D_{2 \text { in }}\right)$ to the same value of $D_{1 \text { in }}$.

(6) Initially, set the transitional section length of the balun $\left(L_{t}\right)$ to zero.

(7) Initially, set the value of the slot width of the split section $\left(\theta_{s}\right)$ to a small value (about $10^{\circ}$ ).

(8) Initially, set $\delta_{i}$ to a relatively small error, for example, $\delta_{i}=0.1 Z_{0}$, where the subscript $i$ means an iterative error in impedance matching.

(9) Given the value of the load impedance on the balanced side of the balun, calculate the input impedance seen at the unbalanced side of the balun using the MoM.

(10) If the absolute value of the impedance mismatch does not satisfy the condition $\left|Z_{\text {in }}-Z_{0}\right|<\delta_{i}$, then go to an iterative technique by changing the values of 


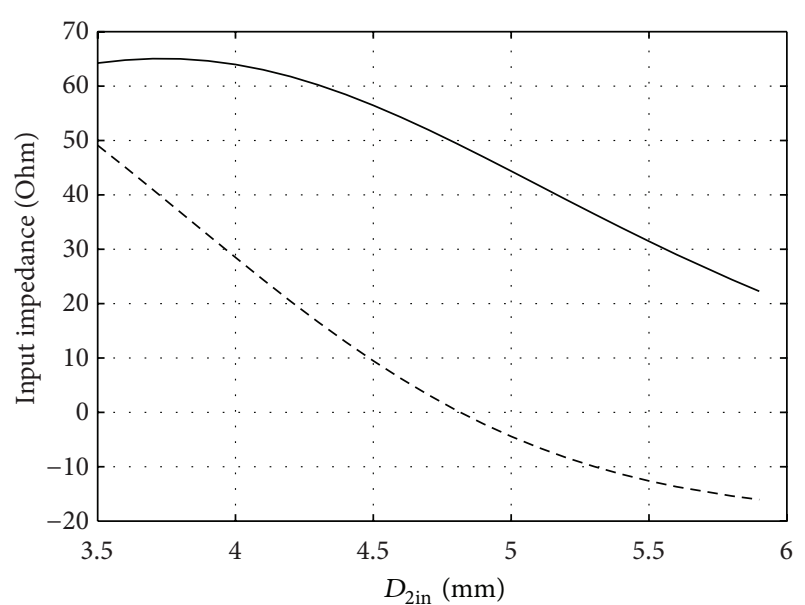

- Resistance

- - Reactance

(a)

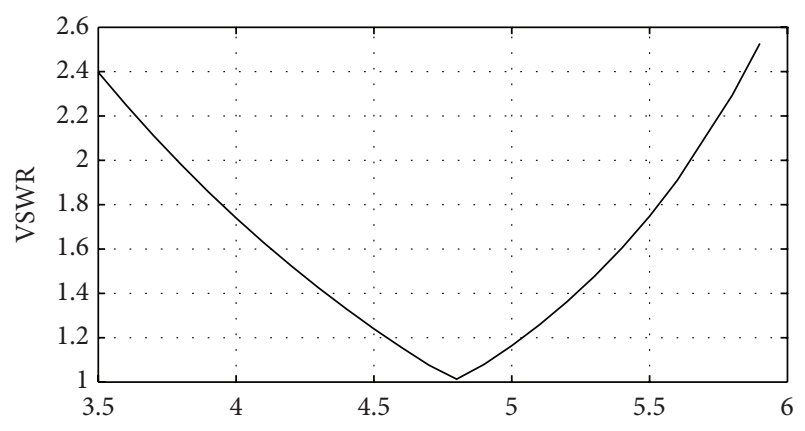

(b)

FIGURE 9: Variation of (a) the input impedance and (b) VSWR of a split coaxial balun excited at the coaxial side and terminated at the twin side by $75 \Omega$ load with the diameter of the inner conductor of the split section of the balun; $f=2.0 \mathrm{GHz}, D_{\text {out }}=8 \mathrm{~mm}, D_{1 \text { in }}=$ $3.5 \mathrm{~mm}, L_{1 \text { out }}=6.72 \mathrm{~cm}, L_{2 \text { out }}=3.44 \mathrm{~cm}, L_{1 \text { in }}=6.34 \mathrm{~cm}, L_{2 \text { in }}=$ $3.82 \mathrm{~cm}, L_{t}=3.8 \mathrm{~mm}$, and $\theta_{s}=40^{\circ}$.

the parameters $L_{t}$ and $\theta_{s}$ to reduce the impedance mismatch as described in the flowchart shown in Figure 6 and using the following rules:

(i) to decrease both $R_{\text {in }}$ and $X_{\text {in }}$, decrease $\theta_{s}$;

(ii) to increase both $R_{\text {in }}$ and $X_{\text {in }}$, increase $\theta_{s}$;

(iii) to increase $R_{\mathrm{in}}$ and decrease $X_{\mathrm{in}}$, increase $L_{t}$;

(iv) to decrease $R_{\text {in }}$ and increase $X_{\text {in }}$, decrease $L_{t}$.

(11) If the absolute value of the impedance mismatch satisfies the condition $\left|Z_{\text {in }}-Z_{0}\right|<\delta_{i}$, then apply Newton's method to search for $\widehat{D}_{2 \text { in }}$, which is the root of $\partial\left|Z_{\text {in }}\left(D_{2 \text { in }}\right)-Z_{0}\right| / \partial D_{2 \text { in }}=0$, that is, the value of $D_{2 \text { in }}$ at which $\partial\left|Z_{\text {in }}\left(D_{2 \text { in }}\right)-Z_{0}\right| / \partial D_{2 \text { in }}=0$. In this way, an improved value of the iterative error, $\delta_{i}$, is determined by $\delta_{i}=\left|Z_{\text {in }}\left(\widehat{D}_{2 \text { in }}\right)-Z_{0}\right|$.

(12) The steps from 9 to 11 listed above are repeated to iteratively reduce the impedance mismatch expressed

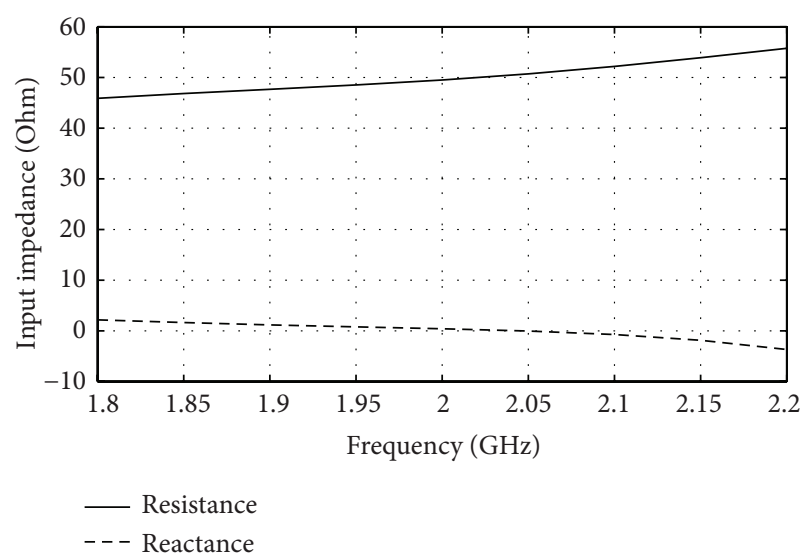

(a)

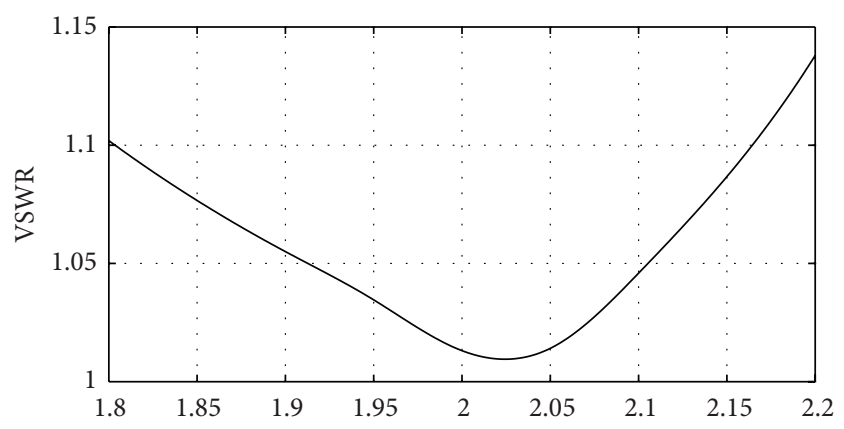

(b)

FIGURE 10: Variation of (a) the input impedance and (b) VSWR of a split coaxial balun terminated by a balanced $75 \Omega$-load with the frequency; $D_{\text {out }}=8 \mathrm{~mm}, D_{1_{\text {in }}}=3.5 \mathrm{~mm}, D_{2_{\text {in }}}=2.4 \mathrm{~mm}, L_{1_{\text {out }}}=$ $6.72 \mathrm{~cm}, L_{2 \text { out }}=3.44 \mathrm{~cm}, L_{1 \text { in }}=6.34 \mathrm{~cm}, L_{2 \text { in }}=3.82 \mathrm{~cm}, L_{t}=$ $3.8 \mathrm{~mm}$, and $\theta_{s}=40^{\circ}$.

by the error $\delta_{i}$ until the stop criterion $\delta_{i} \leq \delta_{\text {stop }}$ is satisfied, where $\delta_{\text {stop }}$ is an acceptable preset mismatch error.

\section{Numerical Results and Discussions}

In the remaining part of the present paper, the effects of the transitional length $L_{t}$, the step change of the inner conductor diameter $\left(D_{2 \text { in }}-D_{1_{\text {in }}}\right)$, and finally the slot angle of the split section $\theta_{t}$ on the input impedance seen at the (unbalanced) coaxial line side of the balun are investigated when it is terminated with specific lumped impedance at its (balanced) split side. Also, the variation of the input impedance with the frequency is investigated when the balun is used to feed (balanced) two-arm antennas such as the strip dipole and the bowtie antenna from (unbalanced) coaxial line.

It should be noted that the MoM is used to get the current distribution on the conducting surfaces and, hence, the input impedance seen at the unbalanced side of the balun. The geometric models of the conducting surfaces are constructed up using triangular patches. The excitation and lumped impedance load models are attached to the geometric model as described in [12]. 
5.1. Dependence of the Input Impedance of the Split Coaxial Balun on Its Dimensional Parameters When Terminated with Balanced Loads. Setting the dimensional parameters of the split coaxial balun with a step transition of the inner conductor diameter, indicated in Figure 2, is the designer problem to match a given load at one side of the balun to a feeder of specific impedance at the other side. In this section, the effects of some dimensional parameters of the balun on its input impedance seen at the unbalanced side are studied assuming that the balun is connected to a specific load at its balanced side.

In the following cases of numerical investigation, the dimensional parameters of the unbalanced side of the balun are set to $D_{\text {out }}=8 \mathrm{~mm}$ and $D_{1 \text { in }}=3.5 \mathrm{~mm}$; this gives a coaxial line section (Section 1) of $50 \Omega$. Also, the total length of this section together with the transitional section (Section 2) is set to $L_{1 \text { out }}=6.94 \mathrm{~cm}$. The length of the split section (Section 3) is set to $L_{2 \text { out }}=3.22 \mathrm{~cm}$.

The effects of the remaining dimensional parameters of the balun are investigated in the following subsections. These dimensional parameters are the inner conductor diameter for the transitional and split sections $D_{2 \text { in }}$, the length of the transitional section $L_{t}$, and the angular width of each slot of the split section $\theta_{s}$.

5.1.1. Dependence of the Input Impedance on the Length of the Transitional Section. The transitional section length, $L_{t}$, plays an important role for impedance matching. Before splitting the outer conductor into two cylindrical strips; the insertion of transitional section causes the field to be more confined in a narrower region by increasing the inner conduct diameter while keeping the outer conductor diameter. The field is then split to be confined between two separate regions between the cylindrical strips and the inner conductor. Due to the symmetry of the split line two modes can propagate: one with electric field configuration of odd symmetry whereas the other mode has its electric field with even symmetry around any plane of symmetry of the split line.

As a demonstrative example, the dependence of the input impedance of a split coaxial balun terminated with balanced $75 \Omega$-load on the length of the transitional section $L_{t}$ is presented in Figure 7. It should be noted that the value of $L_{t}$ is changed by varying only $L_{1 \text { out }}$ and correspondingly $L_{2 \text { out }}$ while keeping $L_{1 \text { in }}$ and $L_{2 \text { in }}$ unchanged. As shown in the figure, the resistive part of the input impedance increases almost linearly with increasing $L_{t}$, whereas the reactive part decreases almost linearly with increasing this dimensional parameter. Using a transitional section length of $L_{t}=4 \mathrm{~mm}$, the balanced $75 \Omega$ load is completely matched to unbalanced $50 \Omega$-feeder. This is clear in Figure 7(b), where the VSWR is very close to 1 at this value of $L_{t}$.

5.1.2. Dependence of the Input Impedance on the Slot Angle. The dependence of the input impedance of a split coaxial balun terminated with balanced $75 \Omega$-load on the angular width $\theta_{s}$ of each of the two slots made in the split section of the balun is presented in Figure 8. As shown in the figure, both the resistive and reactive parts of the input impedance



(a)

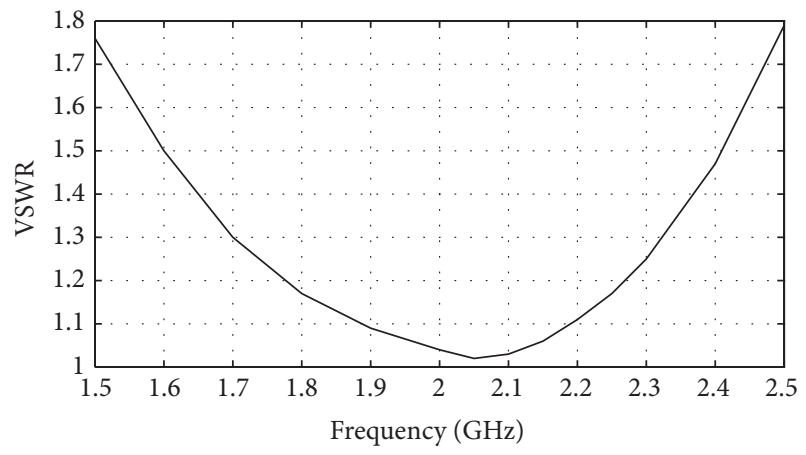

(b)

FIGURE 11: Variation of (a) the input impedance and (b) VSWR of a split coaxial balun terminated by a balanced $140 \Omega$-load with the frequency; $D_{\text {out }}=8 \mathrm{~mm}, D_{1 \text { in }}=3.5 \mathrm{~mm}, D_{2_{\text {in }}}=4 \mathrm{~mm}, L_{1_{\text {out }}}=$ $6.72 \mathrm{~cm}, L_{2 \text { out }}=3.44 \mathrm{~cm}, L_{1 \text { in }}=6.34 \mathrm{~cm}, L_{2 \text { in }}=3.82 \mathrm{~cm}, L_{t}=$ $3.8 \mathrm{~mm}$, and $\theta_{s}=50^{\circ}$.

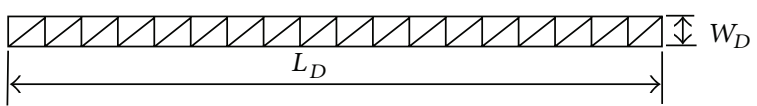

(a)



(b)

FIGURE 12: Geometric model of (a) strip dipole antenna with the dimensional parameters and (b) strip dipole antenna fed through a split coaxial balun (zoom-in view at the feeding location). 


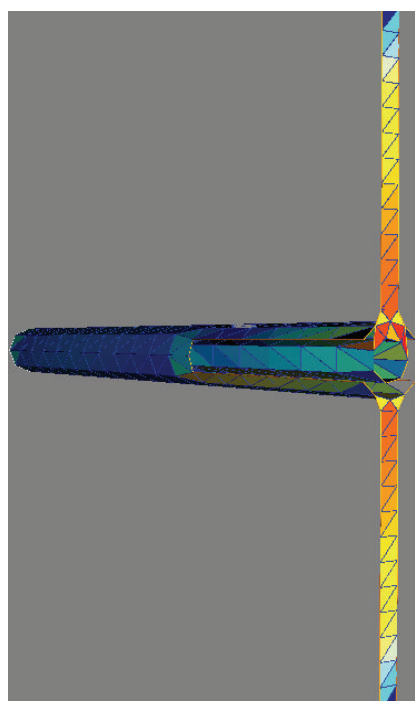

(a)

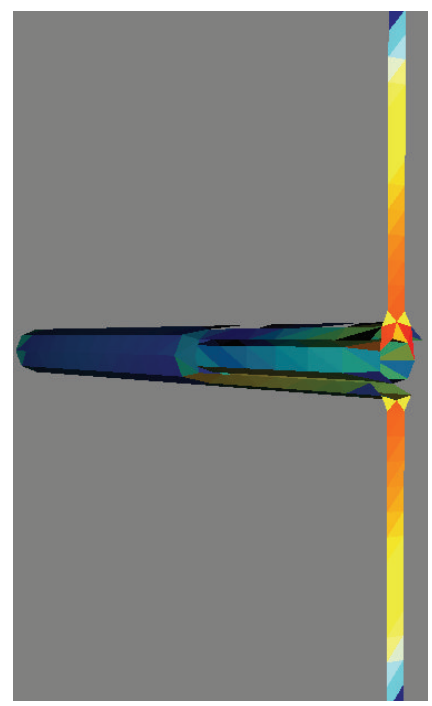

(b)

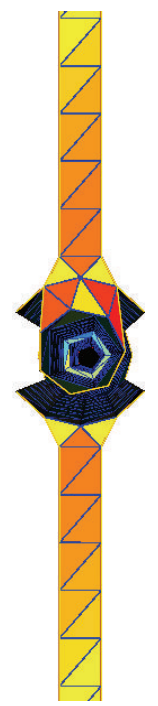

(c)

FIGURE 13: The current distribution on the dipole arms fed through a split coaxial balun with a step transition in the inner diameter conductor on the surface model of the balun and dipole (a) showing the sides of the triangular patches and (b) hiding the sides of the triangular patches, and (c) zoom-in view at the antenna connection with the balun; $f=2 \mathrm{GHz}$.

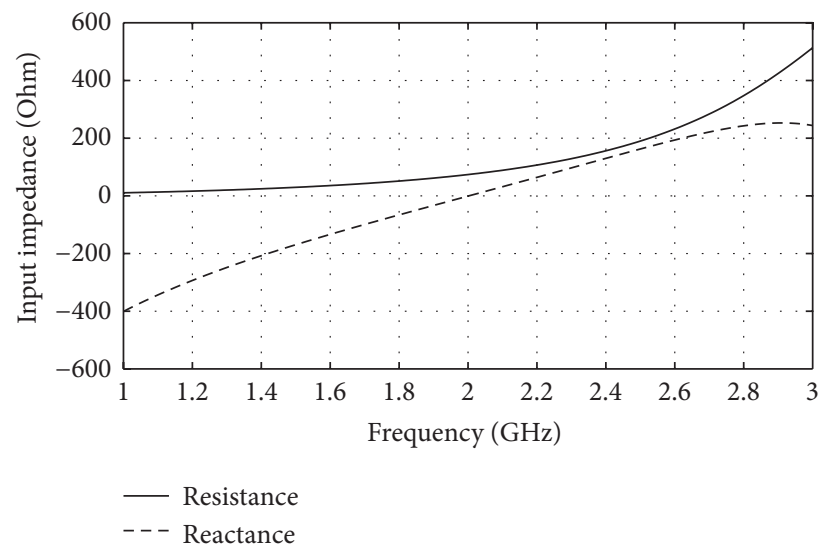

FIGURE 14: Variation of the strip-dipole antenna impedance with the frequency; dipole dimensions: $L_{D}=7.2 \mathrm{~cm}$ and $W_{D}=2.2 \mathrm{~mm}$.

increase nonlinearly with increasing $\theta_{s}$ with almost the same rate of increase. Using angular width of $\theta_{s}=40^{\circ}$, the balanced $75 \Omega$ load is completely matched to unbalanced $50 \Omega$ feeder. This is clear in Figure 8(b), where the VSWR is very close to 1 at this value of $\theta_{s}$.

\subsubsection{Dependence of the Input Impedance on the Diameter} of the Inner Conductor of Split Section. The dependence of the input impedance of a split coaxial balun terminated with balanced $75 \Omega$-load on the inner diameter $D_{2 \text { in }}$ of the split section of the balun is presented in Figure 9. As shown in the figure, the reactive part of the input impedance is inductive for small values of $D_{2 \text { in }}$. Both the resistive and reactive parts of the input impedance decrease nonlinearly with increasing
$D_{2 \text { in }}$. The reactive part of the input impedance vanishes at $D_{2 \text { in }}=4.8 \mathrm{~mm}$. When $D_{2 \text { in }}$ is increased above this value, the input impedance becomes capacitive. For small values of $D_{2 \text { in }}$ the rate of decay of the reactive part with increasing $D_{2 \text { in }}$ is higher than that of the resistive part, whereas for high values of $D_{2 \text { in }}$, the rate of decay of the resistive part of the input impedance is higher than that of the reactive part. Using a balun of inner diameter $D_{2 \text { in }}=4.8 \mathrm{~mm}$, the balanced $75 \Omega$ load is completely matched to unbalanced $50 \Omega$-feeder. This is clear in Figure 9(b), where the VSWR is very close to 1 at this value of $D_{2 \text { in }}$.

5.2. Matching Balanced Arbitrary Load to Unbalanced $50 \Omega$ Feeder. In this section, the split coaxial balun with a step transition of the inner conductor is designed to match balanced loads of arbitrary impedance to unbalanced $50 \Omega$ coaxial line. Two values of the load impedance are investigated: $75 \Omega$ and $140 \Omega$.

5.2.1. Matching Balanced $75 \Omega$-Load to Unbalanced $50 \Omega$ Feeder. A split coaxial balun with the following dimensional parameters can be used to match a balanced $75 \Omega$-load to unbalanced $50 \Omega$-coaxial line at $2.0 \mathrm{GHz}: D_{\text {out }}=8 \mathrm{~mm}$, $D_{1_{\text {in }}}=3.5 \mathrm{~mm}, D_{2_{\text {in }}}=2.4 \mathrm{~mm}, L_{1_{\text {out }}}=6.72 \mathrm{~cm}, L_{2 \text { out }}=$ $3.44 \mathrm{~cm}, L_{1 \text { in }}=6.34 \mathrm{~cm}, L_{2 \text { in }}=3.82 \mathrm{~cm}, L_{t}=3.8 \mathrm{~mm}$, and $\theta_{s}=40^{\circ}$. The variation of the input impedance (seen at the unbalanced side of the balun) with the frequency is shown in Figure 10(a). The corresponding variation of the VSWR is presented in Figure 10(b). The value of the VSWR is maintained below 2.0 over the frequency range (1.2$2.55 \mathrm{GHz}$ ) and, hence, the impedance matching bandwidth can be considered as $1.35 \mathrm{GHz}$. 
5.2.2. Matching Balanced $140 \Omega$-Load to Unbalanced $50 \Omega$ Feeder. A split coaxial balun with the following dimensional parameters can be used to match a balanced $140 \Omega$-load to unbalanced $50 \Omega$-coaxial line at $2.0 \mathrm{GHz}: D_{\text {out }}=8 \mathrm{~mm}$, $D_{1 \text { in }}=3.5 \mathrm{~mm}, D_{2_{\text {in }}}=4 \mathrm{~mm}, L_{1 \text { out }}=6.72 \mathrm{~cm}, L_{2 \text { out }}=$ $3.44 \mathrm{~cm}, L_{1 \text { in }}=6.34 \mathrm{~cm}, L_{2 \text { in }}=3.82 \mathrm{~cm}, L_{t}=3.8 \mathrm{~mm}$, and $\theta_{s}=50^{\circ}$. The variation of the balun input impedance with the frequency is shown in Figure 11(a). The corresponding variation of the VSWR is presented in Figure 11(b). The VSWR is maintained below 2.0 over the frequency range (1.41$2.5 \mathrm{GHz}$ ) and, hence, the impedance matching bandwidth can be considered as $1.16 \mathrm{GHz}$.

It is noticed that the impedance matching bandwidth of the balun when used to match $75 \Omega$-load to $50 \Omega$-coaxial line is wider than the matching bandwidth when it is used to match $140 \Omega$-load to $50 \Omega$-coaxial line. It may be concluded that the balun bandwidth depends on the difference between the two impedances on the sides of the balun; the larger the differences between the impedances to match, the narrower the bandwidth of impedance matching.

5.3. Matching Balanced Antennas to Unbalanced $50 \Omega$-Feeder. In this section, the split coaxial balun with a step transition of the inner conductor is designed to match some practical types of balanced antennas to unbalanced $50 \Omega$-feeder. The dimensions of the balun are the design parameters to be determined. The input impedance and the VSWR, seen at the unbalanced port of the balun, are investigated over wide frequency ranges.

5.3.1. Matching Strip Dipole Antenna to Unbalanced $50 \Omega-$ Feeder. A strip dipole antenna has the triangular-patch model shown in Figure 12(a). To feed this antenna through the conventional $50 \Omega$-coaxial line, the balun is inserted between the coaxial feeder and the antenna as shown in Figure 12(b).

The electric current distribution on the conducting surfaces of the balun as well as that on the arms of the strip dipole is presented in color scale as shown in Figure 13. It is clear that the current magnitudes on both dipole arms are almost identical which means that if the expression given by (3) is used, a high balance ratio is obtained due to the insertion of this balun.

The variation of the input impedance of the strip dipole antenna without using the split coaxial balun is presented in Figure 14. It should be noted that the results presented in this figure are obtained using the finite-width gap excitation model described in [12]. This antenna is designed to operate at $2.0 \mathrm{GHz}$, where the antenna impedance is pure resistive and equal to $75 \Omega$. It is well known that the impedance matching bandwidth of such an antenna when fed through $75 \Omega$-twin feeder (balanced line) is about $10 \%$.

A split coaxial balun is designed to feed this antenna from a $50 \Omega$-coaxial line. The dimensional parameters of the balun are indicated in the comment below the figure. Using this balun, the dependence of the input impedance on the frequency becomes as presented in Figure 15(a). The corresponding variation of the VSWR (considering



- Resistance

(a)

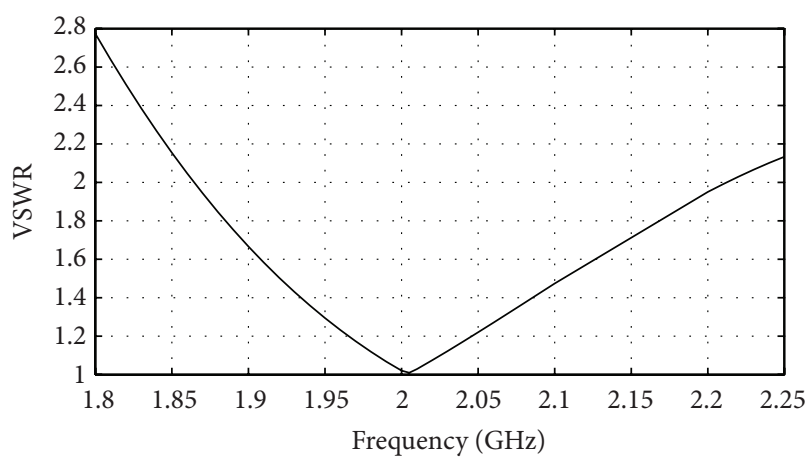

(b)

FIGURE 15: Variation of (a) the input impedance and (b) VSWR of a split coaxial balun feeding a dipole antenna with the frequency for a $50 \Omega$-source; $D_{\text {out }}=8 \mathrm{~mm}, D_{1 \text { in }}=3.5 \mathrm{~mm}, D_{2 \text { in }}=4.7 \mathrm{~mm}$, $L_{1 \text { out }}=6.72 \mathrm{~cm}, L_{2 \text { out }}=3.44 \mathrm{~cm}, L_{1 \text { in }}=6.34 \mathrm{~cm}, L_{2 \text { in }}=3.82 \mathrm{~cm}$, $L_{t}=3.8 \mathrm{~mm}$, and $\theta_{s}=65^{\circ}$. Dipole dimensions: $L_{D}=7.2 \mathrm{~cm}$ and $W_{D}=2.2 \mathrm{~mm}$.

$50 \Omega$-feeder) is shown in Figure 15(b). As shown in both figures, using the split coaxial balun results in almost complete matching at $2.0 \mathrm{GHz}$. The impedance matching bandwidth of the strip dipole antenna fed through this balun is about $17.5 \%$, which is wider than the bandwidth of the conventional dipole antenna when fed through $75 \Omega$-twin feeder.

5.3.2. Matching Bowtie Antenna to Unbalanced $50 \Omega$-Feeder. A bowtie antenna has the triangular-patch model shown in Figure 16(a). To feed this antenna through the conventional $50 \Omega$-coaxial line, the balun is connected to the antenna as shown in Figure 16(b).

The variation of the input impedance of the bowtie antenna without using the split coaxial balun is presented in Figure 17. The results presented in this figure are obtained using the finite-width gap source model described in [12]. This antenna is designed to operate at $2.0 \mathrm{GHz}$, where the antenna impedance is almost resistive and equal to $270+$ $j 10 \Omega$. It is well known that the bowtie antenna has wider bandwidth than that of the conventional dipole antenna.

A split coaxial balun is designed to feed this antenna from a $50 \Omega$-coaxial line. The dimensional parameters of the balun are indicated in the comment below the figure. 




(a)

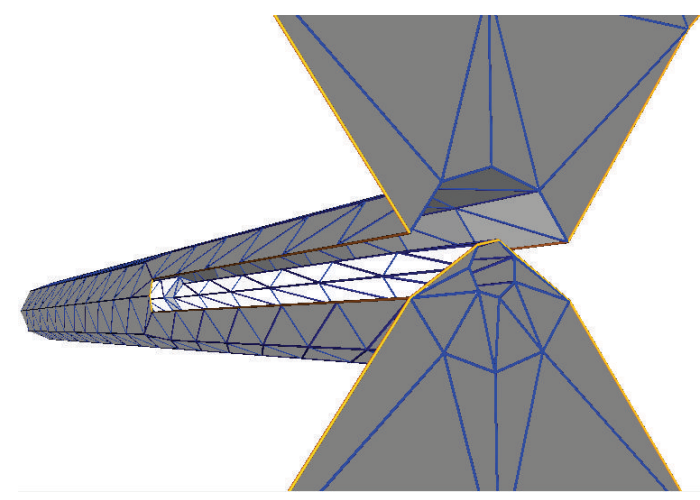

(b)

FIGURE 16: Geometric model of (a) bowtie antenna with the dimensional parameters and (b) bowtie antenna fed through a split coaxial balun (zoom-in view at the feeding location).

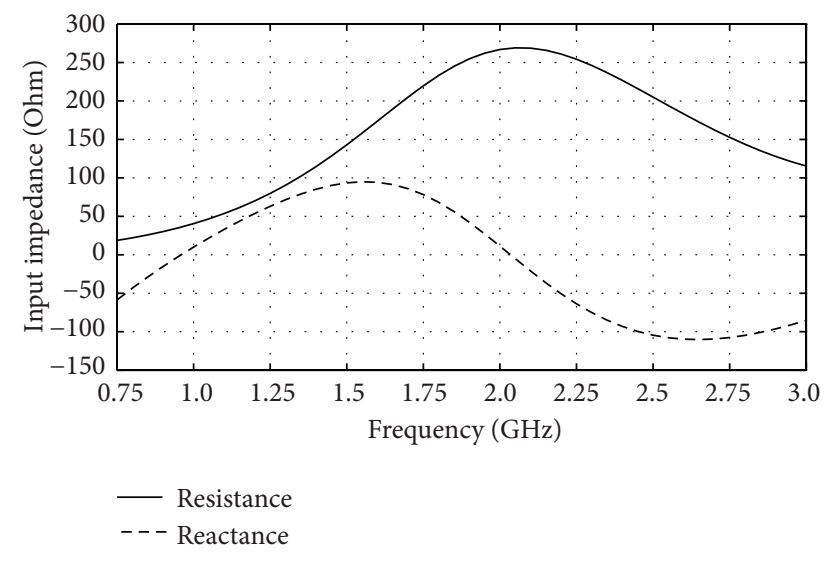

FIGURE 17: Variation of the bowtie antenna impedance with the frequency; $L_{B}=9.525 \mathrm{~cm}, W_{B}=4.5 \mathrm{~mm}$, and $\theta_{f}=45^{\circ}$.

Using this balun, the dependence of the input impedance on the frequency becomes as shown in Figure 18(a). The corresponding variation of the VSWR (considering $50 \Omega$ feeder) is shown in Figure 18(b). As shown in both figures, connecting the balun results in almost complete matching at 2.0 GHz. The impedance matching bandwidth of the bowtie antenna fed through this balun is about $15 \%$. It may be concluded that the relatively low bandwidth of impedance matching in this case can be attributed to the large difference between the bowtie impedance $(270+j 10 \Omega)$ and the coaxial line impedance $(50 \Omega)$.

5.4. Performance Assessment of the Proposed Balun. Figure 19 shows a comparison among the return losses obtained when feeding a strip dipole antenna with (i) a conventional split coaxial balun as designed in [11], (ii) a split balun with a step transition of the inner conductor as optimized in the present work, and (iii) a coaxial line (no balun is used). As clear from the comparison, the balun proposed in the present work has the lowest return loss (about $-47 \mathrm{~dB}$ ) at the design frequency (450 MHz).
A clear disadvantage of the balun proposed in [11] is that it causes a return loss worse than that obtained even when no balun is used to feed the dipole antenna. However, the major advantage of the balun proposed in [11] appears if we consider an acceptable level of the return loss of $-10 \mathrm{~dB}$ (VSWR of about 2.0). In this case, the balun proposed in [11] has a relatively wide bandwidth (of about 23\%) whereas the balun proposed in the present work has a bandwidth of $17.5 \%$.

A more stringent test level of $-14 \mathrm{~dB}$ return loss (VSWR of about 1.5) will lead to unaccepted performance from the split balun proposed in [11] around the design frequency as clear from the plots of Figure 19. However, under this stringent test, the balun proposed in the present work is advantageous and has a bandwidth of about $12 \%$, whereas the dipole fed without a balun has a bandwidth of about $2.5 \%$ regarding impedance matching.

The results of comparison can be summarized as shown in Tables 1 and 2. From the comparison, one can conclude that the split coaxial balun with a step transition of the inner conductor, when used to feed a balanced dipole from unbalanced coaxial line has the ability to be optimized so as to get the best achievable performance (regarding impedance matching) at the design frequency and over a good bandwidth around it. On the other hand, the conventional split coaxial balun results in a higher return loss at the design frequency but, however, keeps a relatively low level of the return loss below $-10 \mathrm{~dB}$ over a wider bandwidth (of about $23 \%$ ). To explain this, it should be noted that the balun proposed in the present work is optimized to get the minimum return loss at the design frequency $(450 \mathrm{MHz})$ rather than to get the maximum band width for a specific value of the return loss.

\section{Experimental Assessment of the Proposed Balun}

For experimental assessment of the proposed balun, a strip dipole is fed through a balun where the return loss is measured through the frequency $1350 \mathrm{MHz}$ to $2750 \mathrm{MHz}$ using a vector network analyzer. The parts of the balun used to feed the strip dipole are shown in Figure 20. The 
TABLE 1: Impedance matching bandwidth for different types of baluns used to feed a dipole antenna from a $50 \Omega$ coaxial line.

\begin{tabular}{lccc}
\hline \multirow{2}{*}{ VSWR (return loss) } & \multicolumn{2}{c}{ Impedance matching bandwidth } \\
& No Balun & Conventional split coaxial balun [11] & Balun proposed in the present work \\
\hline $1.5(-14 \mathrm{~dB})$ & $2.5 \%$ & Not acceptable $(0 \%)$ & $12 \%$ \\
$2.0(-10 \mathrm{~dB})$ & $10 \%$ & $23 \%$ & $17.5 \%$ \\
\hline
\end{tabular}

TABle 2: Performance of different types of baluns used to feed a dipole antenna from a $50 \Omega$ coaxial line.

\begin{tabular}{lccc}
\hline Performance measure & \multicolumn{3}{c}{ Performance at the design (center) frequency } \\
& No balun & Conventional split coaxial balun [11] & Balun proposed in the present work \\
\hline VSWR & 1.50 & 1.73 & 1.01 \\
Return loss & $-14 \mathrm{~dB}$ & $-11.5 \mathrm{~dB}$ & $-47 \mathrm{~dB}$ \\
\hline
\end{tabular}

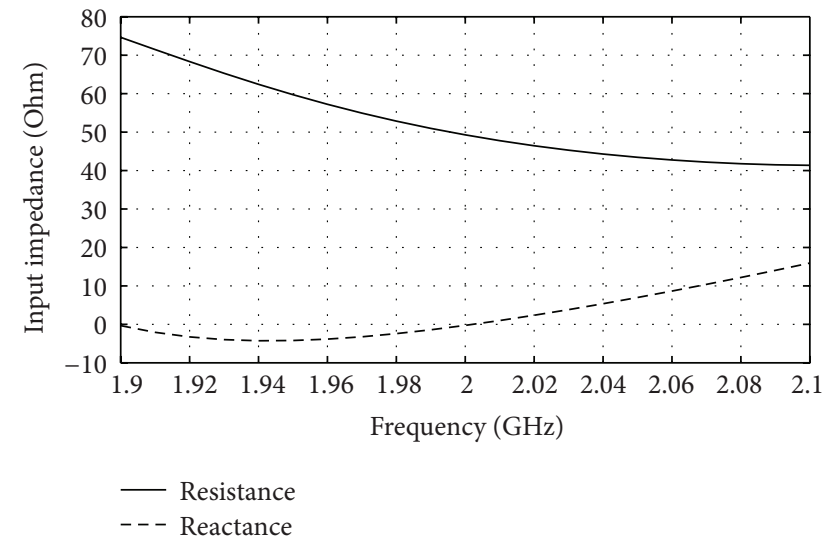

(a)

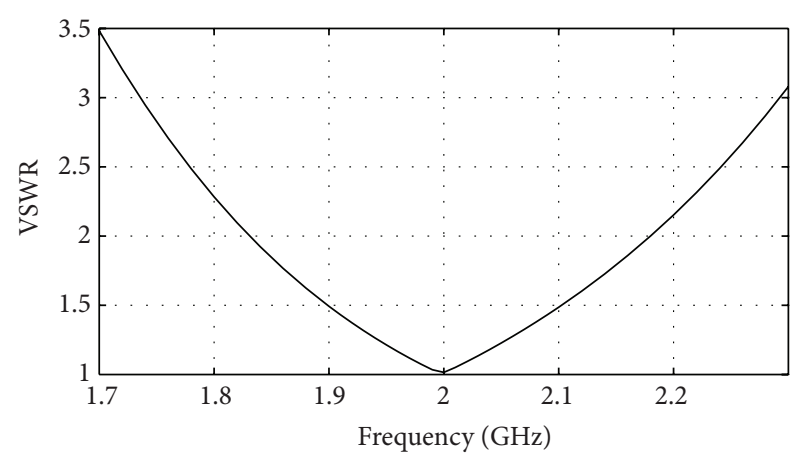

(b)

FIGURE 18: Variation of (a) the input impedance and (b) VSWR of a split coaxial balun feeding a bowtie antenna with the frequency for a $50 \Omega$-source; $D_{\text {out }}=8 \mathrm{~mm}, D_{1 \text { in }}=3.5 \mathrm{~mm}, D_{2 \text { in }}=2.3 \mathrm{~mm}$, $L_{1 \text { out }}=6.72 \mathrm{~cm}, L_{2 \text { out }}=3.44 \mathrm{~cm}, L_{1 \text { in }}=6.34 \mathrm{~cm}, L_{2 \text { in }}=3.82 \mathrm{~cm}$, $L_{t}=3.8 \mathrm{~mm}, \theta_{s}=35^{\circ}$. Bowtie dimensions: $L_{B}=9.525 \mathrm{~cm}, W_{B}=$ $4.5 \mathrm{~mm}$, and $\theta_{f}=45^{\circ}$.

measurement results are compared with the results obtained using the MoM as described in the present work as shown in Figure 21. The dipole antenna dimensions are $L_{D}=7.2 \mathrm{~cm}$, $W_{D}=2.2 \mathrm{~mm}$. The balun dimensions are: $D_{\text {out }}=8 \mathrm{~mm}$, $D_{1_{\text {in }}}=3.5 \mathrm{~mm}, D_{2_{\text {in }}}=4.7 \mathrm{~mm}, L_{1 \text { out }}=6.72 \mathrm{~cm}, L_{2 \text { out }}=$ $3.44 \mathrm{~cm}, L_{1 \text { in }}=6.34 \mathrm{~cm}, L_{2 \text { in }}=3.82 \mathrm{~cm}, L_{t}=3.8 \mathrm{~mm}$, and



FIGURE 19: The return losses against the frequency obtained when feeding a strip dipole antenna with (i) a conventional split coaxial balun as designed in [11], (ii) a split balun with a step transition of the inner conductor as optimized in the present work, and (iii) a coaxial line (no balun is used).

$\theta_{s}=65^{\circ}$. As shown in Figure 20, the experimental results agree with the simulation results obtained using the MoM.

\section{Conclusion}

A split coaxial balun with a step transition of the inner conductor diameter is proposed in the present work. The balun can be seen as composed of three successive sections: coaxial section, transitional section, and split section. The length of the transitional section and the step change of the inner conductor diameter are two additional dimensional parameters (considering the conventional split coaxial balun) that provide more flexibility to design a wideband impedance matching balun. The effects of these dimensional parameters as well as the effect of the slot angle of the split section on the input impedance seen at the (unbalanced) coaxial line side of the balun are investigated when it is terminated with specific lumped impedance at its (balanced) split side. The results show that balun bandwidth depends on the difference between the two impedances on the sides of the balun; the 


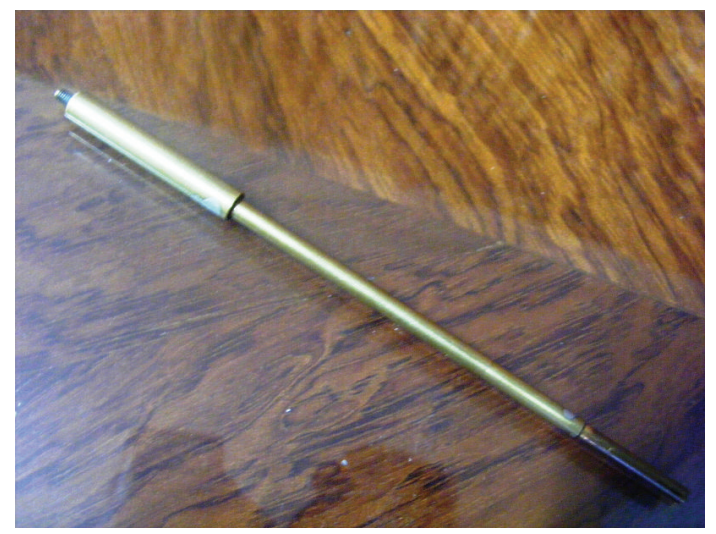

(a)

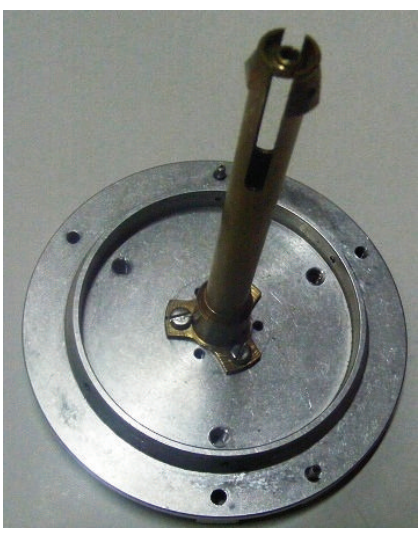

(b)

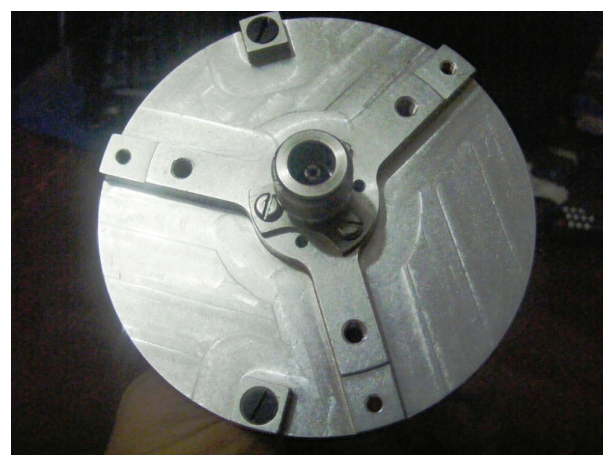

(c)

FIGURE 20: The manufactured balun: (a) the inner conductor with a step transition in its diameter, (b) the doubly-slotted outer conductor mounted on a metal disc, (c) the bottom side of the metal disc with $\mathrm{N}$-type coaxial connector.

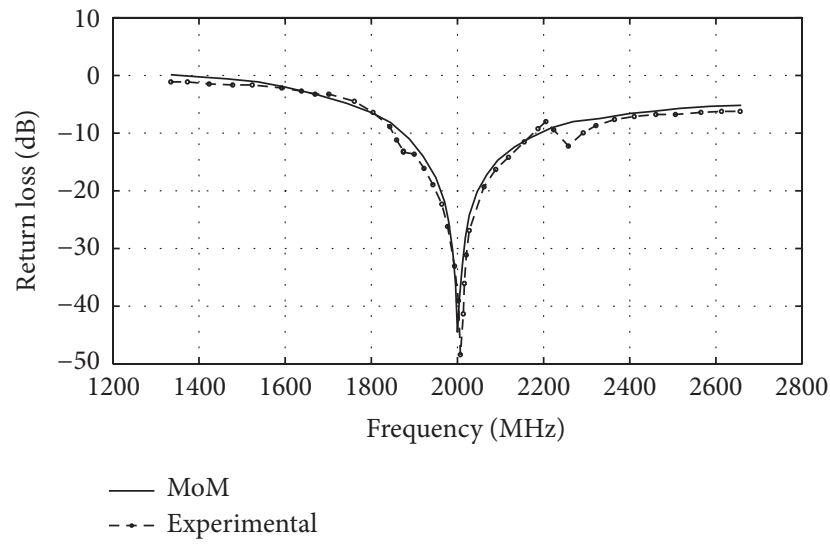

FIGURE 21: The return losses against the frequency obtained when feeding a strip dipole antenna using a split balun with a step transition of the inner conductor as optimized in the present work compared with the experimental results using vector network analyzer.

larger the differences between the impedances to match, the narrower the bandwidth of impedance matching. The proposed split coaxial balun is designed to feed (balanced) two-arm antennas such as the strip dipole and the bowtie antenna from (unbalanced) coaxial line where it is shown that the balun results in antenna impedance matching over a wide frequency band. A comparison with the conventional split balun used to feed a dipole antenna reveals that the balun proposed in the present paper gives a much better performance at the design frequency represented in a much lower value of the return loss and a wider bandwidth for VSWR $\leq 1.5$. The simulation results obtained using the MoM is compared with experimental measurements showing good agreement.

\section{Conflict of Interests}

The author declares that there is no conflict of interests regarding the publication of this paper.

\section{References}

[1] A. J. Hempy, M. P. Civerolo, and D. Y. Arakaki, "Design and assembly of an antenna demonstration system," IEEE Antennas and Propagation Magazine, vol. 54, no. 2, pp. 209-219, 2012.

[2] Y. Hong and J. Yook, "Low-loss broadband planar balun with CPW-to-slotline transition for UHF applications," Journal of the Korean Institute of Electromagnetic Engineering and Science, vol. 9, no. 3, pp. 146-151, 2009.

[3] Z. Zhenyu, The miniaturization and bandwidth enhancement of printed circuit Balun designs for wireless applications [Master 
of Engineering thesis], Electrical and Computer Engineering Department, National University of Singapore, Singapore, 2005.

[4] J. B. Toit, Characterization and phase compensation of a coplanar waveguide to coplanar strip line balun [M.S. thesis], Faculty of Engineering, University of Pretoria, 2009.

[5] M. E. Melais, Design and optimization of broadband planar baluns and Dipole antennas [M.S. thesis], College of Engineering, University of South Florida, 2005.

[6] J. Shao, H. Zhang, C. Chen, S. Tan, and K. J. Chen, "A compact dual-band coupled-line balun with tapped open-ended stubs," Progress In Electromagnetics Research C, vol. 22, pp. 109-122, 2011.

[7] T. Mynttinen, A switchable double-line phase shifter and a metamaterial balun [M.S. thesis], Faculty of Electronics, Alto University, 2010.

[8] R. Smith and S. C. Gripps, "Design of high efficiency, multioctave microwave push-pull power amplifiers," in Proceedings of the Automated Radio Frequency and Microwave Measurement Society Conference, April 2012.

[9] C. Fumeaux, D. Baumann, and R. Vahldieck, "Finite-volume time-domain analysis of a cavity-backed archimedean spiral antenna," IEEE Transactions on Antennas and Propagation, vol. 54, no. 3, pp. 844-851, 2006.

[10] K. Vinayagamoorthy, Design and implementation of wideband Baluns for archimedean spiral antennas [Master of Engineering thesis], Science and Engineering Faculty, Queensland University of Technology, Queensland, Australia, 2011.

[11] S. N. Makarov and R. Ludwig, "Analytical model of the splitcoaxial balun and its application to a linearly-polarized dipole or a CP turnstile," IEEE Transactions on Antennas and Propagation, vol. 55, no. 7, pp. 1909-1918, 2007.

[12] K. F. A. Hussein, "Accurate representation of excitation and loading for arbitrarily shaped antennas composed of conducting surfaces in the method of moments," Progress in Electromagnetics Research B, vol. 36, pp. 151-171, 2012. 

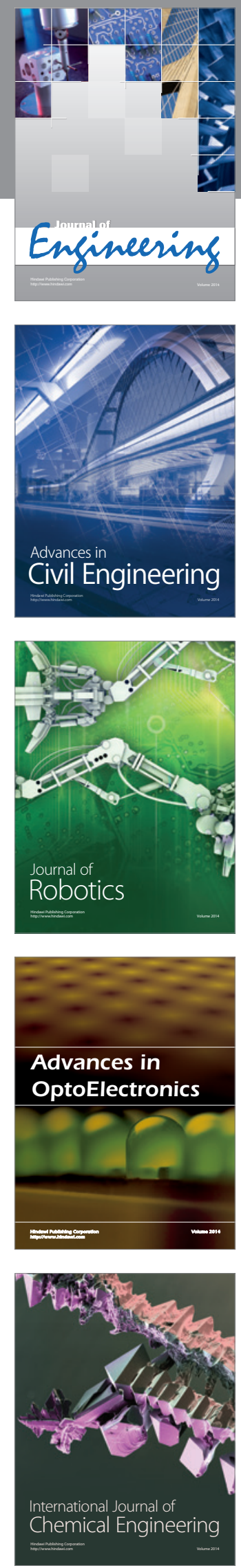

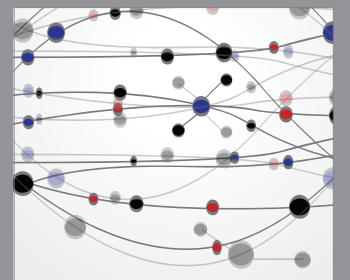

The Scientific World Journal


Submit your manuscripts at http://www.hindawi.com
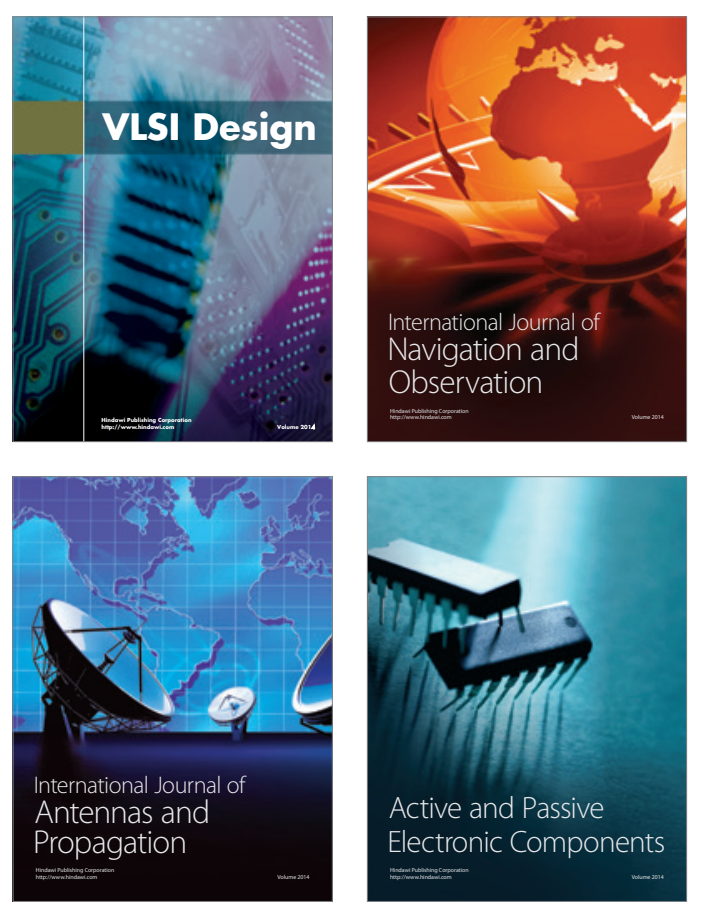
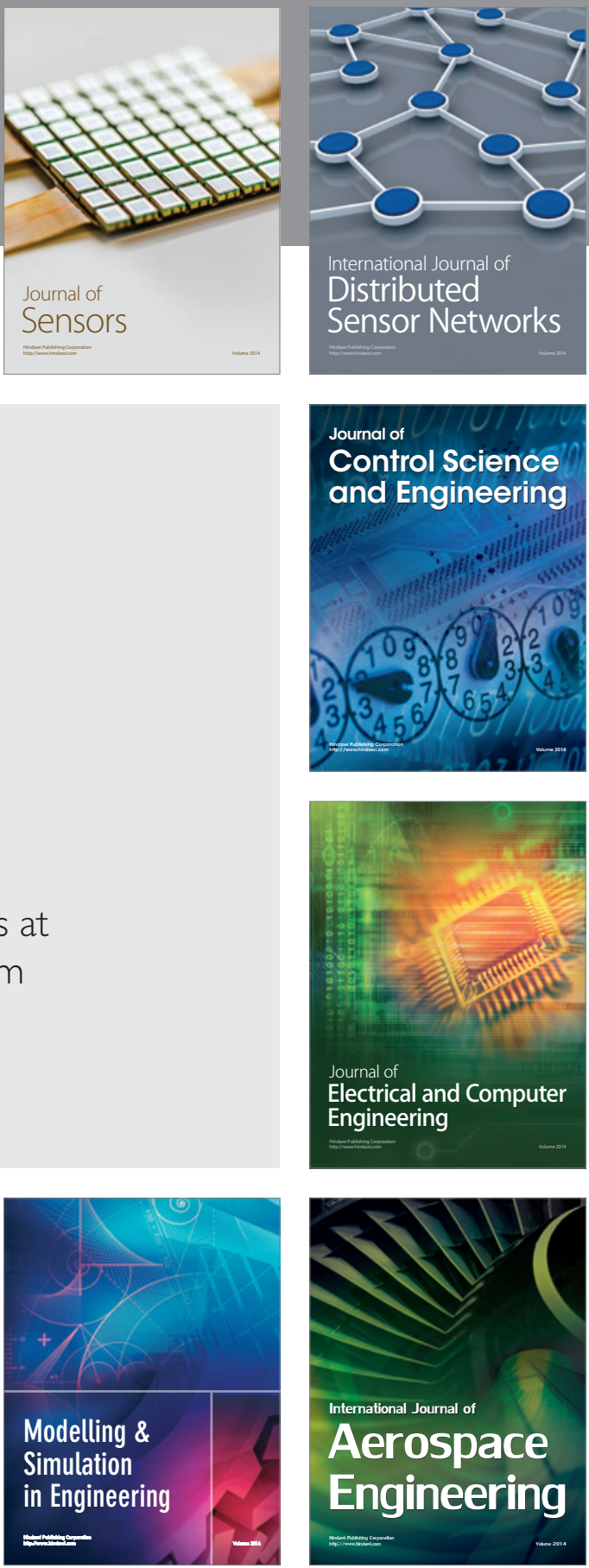

Journal of

Control Science

and Engineering
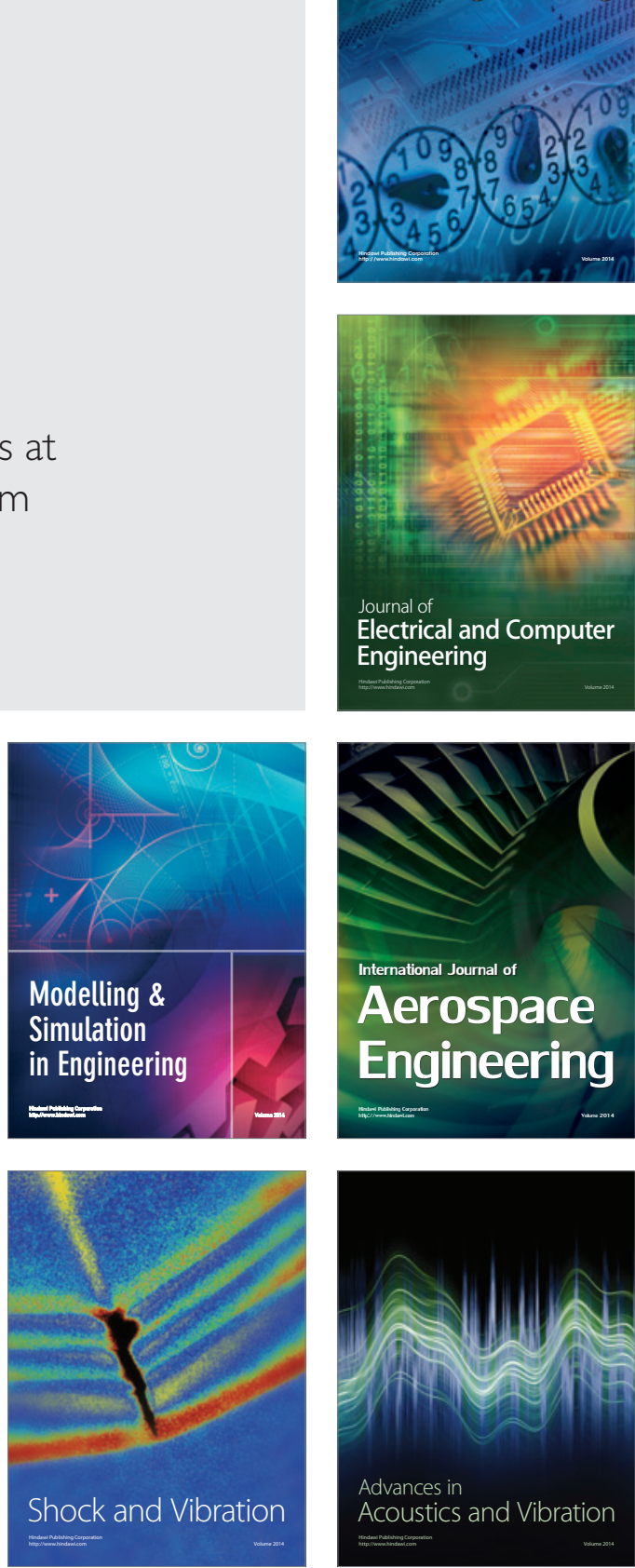